\title{
The Threat and Vulnerabilities of Submarine Cables in Information Security and Telecommunication
}

\author{
Aisha Suliman Alazri \\ Rustaq College of Applied sciences-IT Department
}

Oman

\begin{abstract}
This paper highlights the idea of submarine cables and its security trends. At the beginning, history of cables and its development have been introduced. The main structure of fiber optic has been discussed as well. Finally, threats and vulnerabilities of submarine cable introduced in detail and supported by examples from the world such as natural disaster and habitats, commercial fishing, anchoring, oil and gas development.
\end{abstract}

\section{Introduction}

Nowadays, the world is surrounding by telecommunication technology network in every single area in the planet. This area could be defined as ocean, sea, river, land, air or even space. As a consequence of that, global world is completely shaped as a wired sphere. Obviously, satellites spin in the space for many purposes such as navigation, climate, television and telephone. Therefore, this crafts the space to be crowded of them forming a yard which grants all countries motivation towards arms race. Likewise, undersea surface played an extremely huge effort in the telecommunication part in the world which can be materialized in the submarine cable. Submarine cables shaped a wide network all around the world. Thus, they have been grown up in various directions such as what they are made of, sea laying and security protection. This essay explains how vulnerable they are and how they might be more secure.

First of all, this paper starts by memorable history of telecommunication and submarine cables. Secondly, it will explain what submarine cables and fiber optic cable are undersea and the core difference between a normal fiber optic and a submarine one. Thirdly, it is going to open the door of information security in respect of industry and globalization revolution in addition to distinguishing between advantages and disadvantages. Finally, it will clarify how vulnerable are submarine cables and list some techniques or procedures to improve and enhance the cable's data security.

\section{History of Submarine cables}

Unpredictably by all people, submarine cables carry around $97 \%$ of all telecommunications around the world, whereas satellites count only $3 \%$ or less [1]. This result gives an impression that a satellite is not suitable for easy use and installation. Moreover, it keeps high responsibilities and dependencies of submarines cables in various aspects such as availability, continuity, accuracy and security. However, submarine cables have been passed through long history path. The first submarine cable is configured for telegraph purposes in 1850 [1]. This cable is installed between England and France. Unexpectedly, that worked for only a day and then broke by chafing rocks or because of fishermen as that cable was not armored to fit the sea bed environment. After this event, a need for armored cables appeared as a top priority to connect telegraphs and in a case of safety and protection. This saw the light in 1851 by Robert Stirling Newall and his company. Later on, and after laying some of that cables in some places such as HOLYHEAD HOWTH AND PORT PATRICK-DONAGHADEE, amazing incident happened when the Atlantic telegraph company ordered about 2500 nautical miles of cable and that was made by two different contractors, one to be made by Glass Elliot and another one by Newall company. Both cables were reversed and this caused a fault in the installation after short time in 1858.

An island in The Sultanate of Oman should be highlighted as a part of submarine cable history. This island is called Almaqlab or as named later on, the Telegraph island. It is located to the north west of Oman which takes a strategic position in Hurmoz fjord on the coast of Oman gulf. The history behind this island started after the failure of the Red Sea and India telegraph company cable in 1859 , a failure that left a need to create a new communication plan between Great Britain and India.

Accordingly, the station of cable was built in Almaqlab [2] Island by British cable construction crew to defend the installation against the hostile local attack. In 1868, the cable line was diverted from telegraph Island to Henjam and Jask because of the local inhabitants' attack and some difficulty faced by Turks to complete line construction to Fao. Therefore, cable station in telegraph Island was abandoned and effects are noticed till today. After that period of time, submarine cables started to spread all around the word in a case of telegraph communication and a need for an invention appeared 
indeed for new submarine cables that can withstand all nature challenges and humanity habitats with security aspects.

\section{Manufactures and Structure of Fiber Optic Cable}

Fiber optic cable is the core focal point when telecommunication was taken into account for submarine connection methods. This started to see the light in 1970s when Robert Maurer developed a fiber with a loss of $20 \mathrm{db} / \mathrm{km}$ and then was tremendously produced commercially [5]. The technology behind that invention is to use a light to transmit data via two different systems, one is to convert an electrical signal to light signal and on the opposite bridge is a receiver that again converts that light signal into an electrical one. This technology has stood fiber optic in a high and preferable position in telecommunication industry making the entire world not hesitate to utilize it as a part of a life need. So, what benefits made it in that standard? These are some of them:

1. High bandwidth for data transmission, voice and videos. Its performance can range up to $10 \mathrm{~GB}$. Behind that, also fiber optic ensures future speed for network up to $40 \mathrm{GBps}$ or even 100GBps [6].

2. Long distance. Light signal in fiber optic makes data move with high speed and long distance as well reducing the loss of transmission greatly. Moreover, limitation of distance ranges from 300 meter to 70 Kilometer in accordance with cable style, wavelength and network.

3. Reliability and immunity. Fiber optic is made of glass and for that reason no electric current flow out or less possibility to do so. Also, glass featured manufactured to be isolated. Therefore, immunity exists in case of electromagnetic interference, radio frequency interference, cross talk and impedance problem. In addition, less sensitivity to temperature fluctuation and could be fitted underwater [7].

4. Security. This could be summarized in three basic, firstly because of the made of fiber that does not radio the signal and difficulty behind that to tab. Second, it is easy to monitor any break that could happen to the network. Third, it is also easy to gather all electronics equipments and hardware at one central station.

5. Manufacturing and installation. Fiber optic is easy to handle or to cable because it is small in size, thin and light weighted, it is also easy to test.

Extremely, above all the advantages, fiber optic is a very great solution for telecommunication industry nowadays. Therefore, what is the structure of fiber optic cable which gives it the secret of success in that sector? In the next few paragraphs, this essay tries to present the core manufactures and structure of that great invention.

Fiber optic cable is structured in a way that allows light signal to be transmitted perfectly and as fast as the light speed can run without bending, which causes the signal light to be wasted by any single sharp pending or breaking of glass. Thus, it has been constructed to be flexible and strong using several elements. It consists of a core, cladding, coating buffer, strength member and outer jacket. First of all, core is the pulp of data transmission that carries optical data signals from the light source to a receiving device as a physical medium. It is made of a combination of silica and Germania. The volume of light that the cable can carry depends on its diameter, so a larger diameter width means carrying more lights. Second, cladding is surrounding the core as a boundary containing light waves and keeping light stable in the core because it has less refraction than the core, it is made of pure silica. Third, coating is made of plastic which layer both core and gladding to protect and reinforce them. Forth, strengthening is constructed for the purpose of preventing damage during installation stage as it is required to pull the cable, so it can keep cable stronger. Fifth, as it is named cable jacket, it is the outer layer of the cable and used as a protection against various environmental factors. Moreover, Figure 1 summarizes the construction of fiber optic.

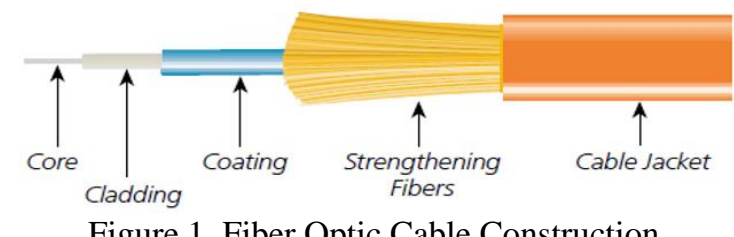

The main principle behind transporting signal in a type of light is based in refraction and reflection of that light. Then, interfacing between the two mediums is affecting any transporting of ray in a type of light that depends on the difference of speed of that light which travels in each material and that material has its own refraction. If this interfacing happened, one of three possibilities is going to happen, and this depends on the incidence angle and critical angle. So, if the incidence angle is less than the critical angle, the light ray will refract; and if they are equal, the light ray will continue traveling towards the surface of interfacing. The third possibility is if the incidence angle is greater than critical angle, the light ray will reflect. The latest possibility is desired to happen to complete propagate of data signals. The refraction index of core is 1.5 and claddings are 1.45 and together have a diameter range between 125 and 440 Um. Figure 
03 illustrates the traveling of light in a fiber cable [6].

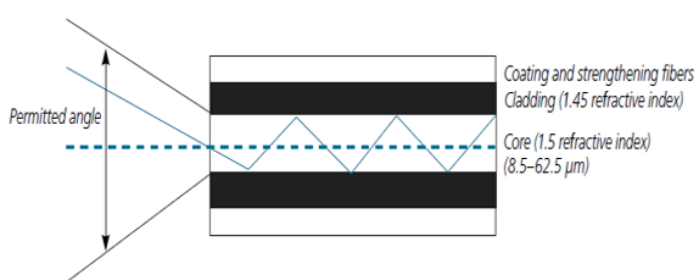

Figure 2. Light Traveling Through a Fiber

There are two main types of fiber optic cable, the first is called single mode cable and the second is multimode cable. Each one of them has its own features and that can be summarized as shown in Table 1.

Table 1. Types and Features of Fiber Optic Cable

\begin{tabular}{|l|l|l|}
\hline Features/Types & Single mode & Multimode \\
\hline Bandwidth & High & Lower \\
\hline Signal quality & High & Lower \\
\hline $\begin{array}{l}\text { Main source of } \\
\text { attenuation }\end{array}$ & $\begin{array}{l}\text { Chromatic } \\
\text { dispersion }\end{array}$ & $\begin{array}{l}\text { Modal } \\
\text { dispersion }\end{array}$ \\
\hline Fiber design & $\begin{array}{l}\text { Step index \& } \\
\text { dispersion } \\
\text { shifted }\end{array}$ & $\begin{array}{l}\text { Step index \& } \\
\text { graded index }\end{array}$ \\
\hline Application & $\begin{array}{l}\text { Long } \\
\text { transmission, } \\
\text { higher } \\
\text { bandwidth }\end{array}$ & $\begin{array}{l}\text { Short } \\
\text { lower } \\
\text { bandwidth }\end{array}$ \\
\hline
\end{tabular}

However, any optical communication system consists of three main parts, transmitter, medium and receiver. A transmitter is also divided into two basic categories, Laser diode and LED (light emitting diode). Table 2 explains the difference between these two categories:

Table 2. The difference between two categories

\begin{tabular}{|l|l|l|}
\hline Characteristic/transmitter & $\begin{array}{l}\text { Laser } \\
\text { diode }\end{array}$ & LED \\
\hline Output power & High & Low \\
\hline Switching speed & Fast & Slow \\
\hline Output pattern & Narrow & Wide \\
\hline Spectral width & Narrow & wide \\
\hline
\end{tabular}

\begin{tabular}{|l|l|l|}
\hline Operating constrains & More & Few \\
\hline Expense & More & Less \\
\hline Use & $\begin{array}{l}\text { Single } \\
\text { mode }\end{array}$ & multimode \\
\hline
\end{tabular}

Similarly, a receiver consists of three components: a detector, an amplifier and a demodulator. Each component has its own job, so a detector converts an optical signal into an electrical one and then an amplifier regenerates the strength of this signal and at last a demodulator extracts the original electrical signal.

As a consequence, submarine cables are made using fiber optic technology with taking into consideration environment and underwater factors. Accordingly, modern submarine cables are designed to resist various environmental circumstances. Figure 2 illustrates the content of modern submarine cable.

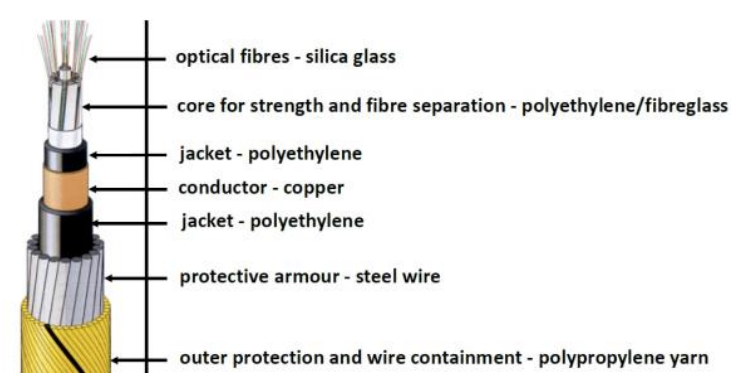

Figure 3. The Content of Modern Submarine Cable

Furthermore, Figure 4 illustrate the construction of submarine cable.

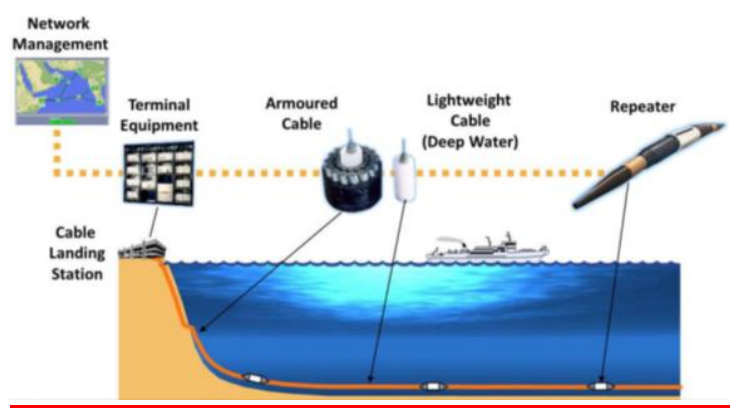

Figure 4. Construction of Submarine Cable

\section{Threats and Vulnerabilities of submarine cables}

Submarine cable continues to carry practically all telecommunications traffic including internet. As a consequence, security of its infrastructure must be kept and protected from any humanity attempts to break down this technology in respect of natural disaster and habitats' attacks. Towards a successful 
implementation and to make submarine cable secure, risks of damage should be taken into account. To begin with, commercial fishing has accounted more than 40 percent of all submarine cable faults worldwide. That percentage of damage is always caused by trawl nets, dredge and long anchor to the seabed. Operators of submarine cables in the United State reduce those risks by burying armored cables in the mud, as well as installing cable awareness and contact programs and paying compensation to fishermen for snagged gear. Those are effective solutions to avoid commercial fishing risks.

Second, the next source of submarine cable damage is anchoring which is caused by vessels anchoring in prohibited sea area usually near installed submarine cables. Anchoring along the sea floor where the submarine cables lay forgetting sea conditions and waves, and in case of an emergency navy vessels or foreign ships anchoring near harbor as a necessity waiting for political entrance approval from certain coastal government. On the east coast of the US, the most common cause of cable breaks and/or fault is caused by fishermen and that occurs in depth of less than 200 meters. Similarly, to the north east coast of the Sultanate of Oman, the most common cause of cable breaks andlor fault is caused by fishing vessels but that occur rarely. Exploring initial solution to this cause is by routing around designated anchoring area. Hence, when any breaks or faulty occurs, the rout is ready to change bath until repair is finished. It takes around two weeks to fix that break, this depends on the contract since that repair is not directed to the government. Moreover, that repair depends on some factors such as how far is the contractor's vessels from the break location are and the weather conditions.

Third, oil and gas development amongst the countries coastal can harm the submarine cables. Unawareness of dangers that oil and gas exploration in submarine cable line causes direct physical disturbance through anchoring exploration materials and fitting new pipelines. Although exploration is most often done by concerned coastal governments, it still needs more cooperation as well as coordination among these governments and all parties that are involved in submarine cables installation and repair. Otherwise, next difficulties will appear while those two stages take place in that area causing complexity and increasing costs and time required to complete them.

Forth, routing submarine cables is a necessity to avoid natural and man-made hazard but that requires clustering cables together which also increases the complexity of installation and maintenance during plowing and grappling operations causing direct or physical disturb to the submarine cables [12].

Fifth, natural disaster like earthquakes and flooding can sever submarine cables as well destroying cable station. For instance, on May 23,
2003, an earthquake in Algeria damaged several submarine cables in the Mediterranean Sea and satellite ground stations [12]. This was the worst case of telecommunication connectivity because it gathered technology, satellite and submarine cable leaving Algeria isolated from the world except for a little international connectivity. Another example happened in Taiwan on $7-11$ August 2009, when Typhoon Morakot hit it causing rivers to flood and carry vast amounts of sediment to ocean and then flowed across the seabed breaking several cables. That influenced internet links, financial market, banking and airline in Taiwan and nearby countries like China and Japan [8].

Similarly, climate change and global warming affect submarine cables negatively via rising sea level due to melting of ice. In addition, global warming increases wave activity giving more possibility for strong storms, rainfalls and floods. Furthermore, that seasonal change in the climate impacts the ability of cable ships for fast installation and maintenance during lying and burying operations.

Another considerable threat is deep sea mining which requires production of support vessels to be anchored all around mining area. In addition to that, remnants of that operation like sulfides and manganese crusts can cause direct physical disturbance of the seabed keeping sea floor busy of equipment, so that could result to suspend submarine cable above the sea floor or surface and then exposed to be severed by fishing net, anchors or even scratched by vessels. In the other words, this impedes installation and maintenance of submarine cables.

Submarine cables are started and terminated with landing stations. As a consequence, how secure are they? It is noticeable that landing stations are not separated far away from public activities and other related governmental activities or private companies. That leads cable ships to have limited access to landing stations amongst the coastal to complete installation of new cables or repair old ones. Moreover, gas and water pipelines infrastructure has a baseline under water and along the beach causing difficulties during burying to connect cables with landing station [9]. In some countries like United State, public roads are very close to landing station and that gives more chances for cars and trucks to park beside the cable station which is, in most cases, not guarded or well fenced [11].

\section{Security of Submarine Cables}

Generally, there is no global system that can detect cable failure before it happens, or even warn related parties to take attention in accordance with any weak signals transfer from a certain cable. Unfortunately, detection of cable failure is known 
after severing which definitely impacts world industrial and economy causing loss of telecommunication connection between countries and that disrupts business activities such as online shopping, banking, financial transaction, etc. Another issue that is worth mentioning here is that in many countries there are always many agencies/parties involved in the submarine cable projects. For instance, in the United States, more than seven agencies are involved in that including Central Intelligence Agency and Department of Navy. Therefore, if any cable failure occurs, it is very cumbersome to coordinate between all parties to detect the exact location of that failure.

As discussed previously, cable awareness program and liaison programs have been implemented and shared with commercial fishing fleets and fishermen as a solution to avoid risks that could be caused to submarine cables. Those programs include charts and maps of submarine cables locations and routing positions which in fact increase the possibility of terrorism attacks as these charts and maps are shared in public websites and accessed by the globe. An example case happened in Southeast Asia on March 23, 2007, when a Vietnamese fishing trawler removed undersea submarine cable intending to sell it in the black market. Repairing that fault cost around $\$ 8$ million and took over three months and of course that terrorist act caused loss of data traffic between United States and Southeast Asia [1].

A study which has been conducted by the communication security reliability and interoperability council (CSRIC) in the USA, recommended that establishment of a default minimum separation distances between an existing submarine cables and another marine or coastal activities will have an advantage to protect submarine cables. That study stated that more than five countries like United Kingdom, China, Russia, Japan, Denmark, Singapore and Indonesia have benefits. For instance, National Maritime Law in Singapore allows submarine cables owner to establish a protection area around them and if any vessels cause any break to those cables, they are responsible to indemnify cable owner. Another example is from China that also determines a specific distance zones around submarine cables such as 50 meters in harbor area, 100 meters in narrow coastal water area and 500 meters in broad coastal water [12]. In fact, this will solve major vulnerabilities such as fishing vessels, anchoring and all marine activities which may cause submarine cable fault.

Another perspective of view suggested by Captain Douglas R. Burnett, a USA retired officer, that it is time for navy to look after cables under seas. He recommended that naval forces need to know how cable and cable ships operate internationally and highlighted to maritime security to close the gap indicated out of the territorial water against terrorism and piracy which in most cases pirates freed because of time consuming to bring them to justice and some political relationships. It is in advance to say that whether naval forces and maritime security playing these roles to protect undersea cables will affect positively in accordance with fast cooperation and response between all related countries. On the other hand, if political or commercial intentions conflict with related countries which are advanced in submarine cables, terrorism and piracy actions will never be under control because that requires united collaboration to be finished.

Moreover, the International Cable Protection Committee (ICPC) which was established in 1958 is an international committee leading submarine cables industry association and until last year, around 143 members from 60 different countries joined [12]. That number of members is not satisfactory because in all countries there is more than one representative, so ICPC is required, among its many activities, to convince remained countries to join that committee for the purpose of global standard to submarine cables installation, operation and protection. Thus, that definition of minimum required standard could be assigned as agreement between all parties later on leading towards worldwide security of submarine cables. Such regimes and rules might be applied independently inside the coastal areas of each country learning form Australian and Singapore experience in that part which are counted as the best countries around the world. These countries implemented practical rules; moreover, they created only one contact point against any attack or cable failure to avoid the long scenarios of coordination between all related parties to protect undersea cables.

In parallel with international laws, an invention must appear; it should provide the possibility of examining and warning submarine cables' owners about any suspected attack or cut before it happens in order to prevent break of cable or even limits failure of data traffic. It will work like an antivirus program or firewall in the operating system. Such effort exists, it is Autonomous Undersea Vehicle (AUV) that could inspect undersea cables regularly but that is not fully functioning as it's expected to do so for some vulnerabilities. First, that effort is owned by civilian companies which put an accusation that could be utilized for spy goals. Second, it has limited access to deep depth of ocean and in many cases it's lost forever.

\section{Conclusion}

In the past, potential threads were limited to fishermen and sharks and that have been resolved because no action of cable cut is noted by shark bite 
for the past few years because using armored submarine cables is enough to keep big fishes and sharks away. On the other hand, these days' challenges of submarine security increased more in accordance with terrorism, piracy, development of offshore energy, population increase, oil and gas infrastructure, wind energy, current and waves energy, wars and conflicts between nations, increase in demands of undersea cables, etc.

Above all, vulnerabilities of submarine cables could cause the entire global telecommunication to break down affecting all sectors such as banking, airlines, financial departments and commercial, and that will impact the globe economy and relationships. Furthermore, nowadays internet is the most important service that humanity benefits from, at both individual and business levels, and it becomes as a food need for most of nations indeed. Thus, keeping the network of all telecommunication sectors in a line is the responsibility of all in the planet. Always challenges exist in our lives but that increases our insistence and determinations to never forgive that who wants to destroy our telecommunication network system on the earth.

\section{References}

[1] Douglas R. Burnett, Robert Beckman, Tara M. Davenport, 'Submarine Cables: The Handbook of Law and Policy', First Edition, Martinus Nijhoff Publishers, Boston, 2014.

[2] lionel Carter, 'Submarine Cables and the Oceans: Connecting the World' , first edition , UNEP/Earthprint, UK, 2009

[3] Burns, B., 'History Of The Atlantic Cable \& Submarine Telegraphy - Wire Rope'. Atlantic-cable.com,31 August 2010, http://atlantic-cable.com/Article/WireRope/Wire rope.htm

[4] Burns, B., 'History Of The Atlantic Cable \& Submarine Telegraphy - Telegraph Island, Oman', Atlantic-cable.com, 22 February 2015, http://atlantic-cable.com/CableCos/TelegraphIsland/

[5] Transition Network, 'Fiber Optics Basics', 1st ed, 2015. Access date: 14 August 2015, http://www.transition.com/ TransitionNetworks/Uploads/Literature/fiber_wp.pdf

[6] Black Box,' Fiber Optics technology-principles and advantages', 1st ed, 2015. Access date: 3 July 2015, https://www.blackbox.com/resource/genPDF/WhitePapers/Fiber-Optic-Technology.pdf

[7] Research Gate, ' what are Fiber Optics, Access date: 7 July 2015, http://www.researchgate.net/file.PostFile Loader.html?id=551e61f0cf57d74e348b45dd\&assetKey= AS\%3A273749050363904\%401442278267254.
[8]'About Submarine Telecommunications Cables', International Cable Protection Committee Ltd, October 2010, https://www.iscpc.org/documents/?id=1753.

[9] Michael Matis, 'The Protection of Undersea Cables: A Global Security Threat', USA, 07 March 2012, http://www.dtic.mil/dtic/tr/fulltext/u2/a561426.pdf

[10] Burnett, D.R., "Cable Vision', USA, August 2011, http://www.squirepattonboggs.com/ /media/files/insights/ publications/2011/08/cable-vision/files/cablevision burnettaug11/fileattachment/cablevisionburnettaug11.pdf

[11] Characteristics And Common Vulnerabilities Infrastructure Category: Petroleum Refineries', Department Of Homeland Security, Usa, 15 January 2004, Http://Viktorvoksanaev.Narod.Ru/Dhs-Refinery-Cv.Pdf

[12] CSRIC, "Protection of Submarine Cables Through Spatial Separation”, December 2014, https://transition.fcc. gov/pshs/advisory/csric4/CSRIC_IV_WG8_Report1_3Dec 2014.pdf 